\title{
Better Usability and Technical Stability Could Lead to Better Work-Related Well-Being among Physicians
}

\author{
Suvi Vainiomäki ${ }^{1,2}$ Anna-Mari Aalto ${ }^{3}$ Tinja Lääveri, ${ }^{4,5}$ Timo Sinervo ${ }^{3}$ Marko Elovainio ${ }^{3,6}$ \\ Pekka Mäntyselkä7,8 Hannele Hyppönen ${ }^{3}$
}

${ }^{1}$ Welfare Division, City of Turku, Turku, Finland

2 Unit of General Practice, University of Turku, Turku, Finland

Address for correspondence Suvi Vainiomäki, MD, Welfare Division,

3 Unit of Social and Health Systems Research, Department of Health and Social Care Systems, National Institute for Health and Welfare, City of Turku, Luolavuorentie 2, Turku 20100, Finland Helsinki, Finland

${ }^{4}$ Division of Infectious Diseases, Inflammation Center, Helsinki University Hospital, Helsinki, Finland

5 Oy Apotti Ab, Helsinki, Finland

${ }^{6}$ Institute of Behavioural Sciences, University of Helsinki, Helsinki, Finland

7 School of Medicine, General Practice, University of Eastern Finland, Finland

8 Primary Health Care Unit, Kuopio University Hospital, Kuopio, Finland (e-mail: sujova@utu.fi).

Appl Clin Inform 2017;8:1057-1067.

\section{Abstract}

\section{Keywords}

- electronic patient records and systems

- patient records

- specific software

- clinical IT systems

- usability

- workflows
Background and Objective Finnish physicians have been increasingly dissatisfied with poor usability of the electronic patient record (EPR) systems, which they have identified as an overload factor in their work. Our aim is to specify which factors in EPRs are associated with work-related well-being of physicians.

Methods A web-based questionnaire was sent to Finnish physicians younger than 65 years; the responses $(n=3,781)$ represent one-fourth of these. This was a repetition of a survey in 2010 , where this questionnaire was used for the first time. In addition to statements assessing usability, there were questions measuring time pressure and job control. The relation between usability and work well-being was investigated with hierarchical multivariate regression analyses: With time pressure and job control as dependent variables, EPR usability assessments and physicians' background information were used as independent variables.

Results In the multivariate analyses, technical problems that are often experienced in the EPR were related to higher time pressure and lower job control. Active participation in the development of the EPR system was related to stronger time pressure and stronger job control. In addition, use of several systems daily and the experience of time-consuming documentation of patient information for statistical purposes (billing, national registries, and reporting) were related to higher time pressure, while those with longer experience with the EPR system and those experiencing easy-to-read nursing records reported higher job control.

Conclusion To relieve time pressure and increase sense of job control experienced by physicians, usability, integrations, and stability of the EPR systems should be improved: fewer login procedures, easier readability of nursing records, and decreased need for received

June 9, 2017

accepted after revision

September 6, 2017
DOI https://doi.org/

10.4338/ACI-2017-06-RA-0094

ISSN 1869-0327.
Copyright () 2017 Schattauer

License terms

(c) (1) $\ominus$ (5) 
separate documentation for statistical purposes. Physician participation in the EPR development would increase the feeling of job control, but would add the time pressure. Hence, time for developmental work should be arranged.

\section{Background and Significance}

Electronic patient records (EPR) have become one of the central tools in physicians' daily work. EPRs are expected to improve the quality and continuity of care, but they have also changed physicians' workflows, documentation time, and documentation practices. ${ }^{1-4}$

In a study conducted by the American Medical Association (AMA), the introduction of EPR systems impaired physicians' professional satisfaction. ${ }^{5}$ This is ascribed to several factors such as poor usability, tedious data entry, interference with direct patient care, inept and less meaningful work content, and an inability to exchange health information. ${ }^{5}$ In Finland, EPR usage is associated with an increase in mental strain as well as poor well-being and work ability among physicians in both a longitudinal questionnaire study and a cross-sectional investigations: ${ }^{6-8}$ physicians consider poorly functioning EPRs as the major factor increasing their work load and physicians working in public sector experience more stress due to EPR usage than their colleagues in the private sector. The work-related well-being of nurses seems less affected by EPR usage than that of physicians. ${ }^{9}$

In our own studies, Finnish physicians are dissatisfied with the usability of their EPR systems. ${ }^{10-15}$ Moreover, the experienced usability does not improve during the 4 year study period (2010-2014) ${ }^{10,13}$ and physicians link faulty functions in EPR systems with an endangering of patient safety. The earlier studies from our data have focused on usability of EPR and HIE (health information exchange) systems. The questionnaire measures for work-related well-being and analysis of their predictors have not been previously reported. In international studies, physicians report that the time taken for documentation has increased and the information systems divert concentration from patient care. ${ }^{16,17}$ Physicians experience that the patient-doctor relationship is negatively affected by the usage of these systems. ${ }^{18}$

\section{Health Information Technology in Finland}

In Finland, health care is publicly funded for the most part and thus private sector is relatively small. Public health care consists of primary care-health care centers employing general practitioners and nurses-and secondary care-hospitals with specialized inpatient and outpatient care. Private sector comprises mostly of specialist clinics and only few hospitals. Practically, all critically ill patients are treated in public hospitals; there are no private intensive care units (ICUs). In Finland, all public health care organizations, both in primary care and hospitals, as well as the vast majority of private care providers use EPRs. ${ }^{19}$ At the time of this survey, the national eprescription functionality was fully implemented in all public sector and part of the private sector EPR systems. By contrast, the national electronic data repository only functioned in one small hospital district. Nevertheless, the new requirements for the implementation of these functionalities had already generated changes and new features in the EPR systems. After the categorization of EPRs as medical devices in 2010, the numbers of EPR-related patient safety incidents reported to the National Supervisory Authority for Welfare and Health (Valvira) increased rapidly. ${ }^{20,21}$

\section{Work-Related Well-Being of Finnish Physicians}

Time pressure, job control, and organizational justice are recognized as important factors for the well-being and health of physicians. ${ }^{22-25}$ Studies suggest that experience of being hurried and patient-related stress are the main reasons for the mental pressure experienced by Finnish physicians. ${ }^{26,27}$ In Finland, physicians and nurses tend to have more mental strain and psychological problems than other personnel: ${ }^{25}$ a cohort study from 2007 found physicians to have double the overall mortality risk and a 3.9 times higher risk of suicide mortality than other health care personnel. High levels of psychological stress and sleeping problems also increase the tendency of physicians to change profession. There is no significant change in overall experienced workload during study years 2006, 2010, and 2015. ${ }^{7}$ Physicians working in primary care report more time pressure and more load factors than their peers in secondary care and the private sector. Patient-related stress seems to be more common among younger physicians working in the primary care sector. One-fifth of Finnish physicians report having experienced a serious threat of burnout and half of the physicians have thought about burnout from time to time.

\section{Research Related to EPRs' Implementation and Work Well-Being}

EPR usage is associated with physicians' mental strain and work-related well-being. ${ }^{5-7,28}$ While most studies focus on factors related to the implementation and deployment phases of health information technology (IT), only a few studies report the impact on physician work well-being of the usage of the established EPR systems.

EPR implementation has been shown to increase the time taken for the documentation of patient information and affect physician workflow. The study of Mamykina et al revealed a high level of fragmentation of documentation activities and frequent task transitions in EPR usage. ${ }^{16}$ They argued that electronic documentation adversely affects the quality of clinical work, increases physicians' mental load, and results in more frequent interruptions, thus presenting a risk to patient safety. Munyisia et al found that electronic nursing documentation system did not reduce time taken for documentation because paper documentation was used alongside EPR. ${ }^{29}$ A time motion study of otolaryngology 
residents found that the residents spent more time in indirect patient care with EPR than directly caring for the patient. One of the suggested reasons for this was the use of EPRs, which results in fragmentation of clinical workflows. ${ }^{17}$ In another study, EPR implementation had a major impact on the physician's time usage for documentation in ICU, and also shifted the pattern of temporal tasks. ${ }^{30}$

\section{Objective}

Identification of EPR features that could ameliorate physicians' work-related well-being has become necessary. The primary aim of the present study is to analyze the relationship between EPR-related factors and the time pressure and job control perceived by physicians.

\section{Methods}

\section{Data Collection}

In February 2014, an electronic questionnaire on the usability of EPRs was sent to all Finnish practicing physicians younger than 65 years $(n=18,257)$. The full questionnaire is available in English. ${ }^{31}$ The survey was first performed in 2010 and repeated in 2014. The usability-focused questionnaire comprised 18 background questions and 38 core statements with a five-point Likert scale; in addition, there were groups of questions addressing issues of management, patient safety, work well-being, information systems development, and EPR features that are working well or are considered as the most important development targets. The questionnaire was designed to focus on physicians work and their use on EPRs, not on a specific software or system or user interface without the context of physicians work. Compared with the standardized usability questionnaires (such as SUMI, QUIS, or SUS), the strength of our questionnaire is that it is designed to focus on easiness, efficiency, and quality of physicians' key tasks performed with the help of the clinical IT systems as tools. Standardized usability questionnaires cannot capture this task- and context-specific variation. The method has been described in detail in our previous articles. ${ }^{32,33}$ The questionnaire 2014 was piloted with eight physicians. National and international articles ${ }^{10-15,33}$ about the usability of different EPR brands have been published. This article is the first to address work well-being.

\section{Respondents}

The 3,781 responses represent approximately one quarter (23.1\%) of Finnish physicians working in patient care. The representativeness was assessed by comparing sample to the register of the Finnish Medical Association (FMA) and to Finnish physician labor market survey of $2014 .^{34}$ Methodologically, the survey sample can be regarded as a representative random sample of the population: ${ }^{13}$ the proportion of respondents representing specialized care (46.4\%) and primary care (24.4\%) were similar to the FMA register; however, the proportion of women had increased and the proportion of younger age groups were slightly smaller than that in the FMA population.

\section{Measures}

\section{Time Pressure and Job Control}

Time pressure and job control were measured by scales, which have been frequently used in studies on psychosocial working conditions of physicians. ${ }^{6,8,28}$ Due to the long questionnaire, shortened versions of the scales were used in the current study. Time pressure was measured by two items derived from the Harris' stress index. ${ }^{35,36}$ The respondents were asked how often they had been disturbed by (1) a constant rush and pressure due to uncompleted work and (2) not enough time to perform work properly. The items were responded on a 5-point scale: 1 = quite often or constantly, 2 = rather often, $3=$ sometimes, $4=$ rather seldom, $5=$ very seldom or never. For computing a composite score (a mean of responses), the scale was reversed so that higher score indicated higher time pressure. The Cronbach's $\alpha$ coefficient for the scale was 0.91 .

Job control was measured by two items: (1) "I am allowed to take independent decisions in my work" and (2) "I have a great deal to say in my own work," derived from the threeitem decision authority subscale from Karasek's job content questionnaire. ${ }^{37}$ The items were responded on a 5-point scale: $1=$ completely agree, $2=$ somewhat agree, $3=$ not agree nor disagree, $4=$ somewhat disagree, $5=$ completely disagree. For computing a composite score (a mean of responses), the scale was reversed so that higher score indicated higher job control. The $\alpha$ coefficient was 0.72 .

\section{Respondent Characteristics}

Age (in years), gender, specialization (nonspecialized, specialization on going, and specialized), health care sector (public/ private), and employer (health center/hospital/private practice or hospital) were selected as background factors.

\section{Respondents' EPR Usage}

The respondents were asked to select the principal brand of EPR system they use in patient care and give an assessment of the system. In addition, the questionnaire included questions about the length of use of the principal EPR system (response alternatives: less than a year/1-3 years/3-6 years/over 6 years), the number of clinical systems that need to be logged into on a daily basis when working with patients (response alternatives: maximum $1 / 2 / 3 / 4$ or more), and participation in the development work on electronic information systems (no/somewhat/ actively).

\section{EPR Usability}

Usability of the (main) EPR system was assessed by a set of 36 items, which were grouped in seven dimensions based on explorative factor analysis (see - Appendix). The seven factors with eigenvalues (eigenvalue measures the variance in all variables which the factor accounts) above 1 explained $55 \%$ of the variation in items. For interpretation of the content of the factors, Varimax rotation (orthogonal rotation) of the factor axes was used to maximize the variance of the squared loadings of a factor (column) on all the variables (rows) in a factor matrix, which has the effect of differentiating the original variables by extracted factor. In the Varimax- 
rotated solution, nine items reflecting the usability of the system received strong loadings in the first factor (loadings $0.40-0.75$ explained the variance of $13 \%$, which was the strongest loading for the first factor, the item "The arrangement of fields and functions is logical on the computer screen"). The Cronbach's $\alpha$ of the total scale composed of all nine items (User friendliness) was 0.88 .

For the second factor, seven items reflecting the perceived benefits of the electronic information system received the strong loadings $(-0.39,0.64-0.79$, explained a variance of $11 \%)$, the strongest loading for the item "Information systems help to improve the quality of care"). The Cronbach's $\alpha$ of the total scale composed of these seven items (Perceived benefits) was 0.84 (in items where the negative loading coding was reversed).

The third factor comprised six items reflecting technical problems or technical stability (loading -0.69 to -0.43 , -0.64 to 0.72 , explained a variance of $9 \%$, the strongest loading for the item "Information entered/documented occasionally disappears from the information system"). The Cronbach's $\alpha$ of the total scale composed of these six items (Technical problems) was 0.82 (in items where the negative loading coding was reversed).

The fourth factor was the four items reflecting the responsiveness of the system supplier to the user feedback received (loadings $0.49-0.83$ explained a variance of $7 \%$, the strongest loading for item "The system vendor implements corrections and change requests according to the suggestions of end-users"). The Cronbach's $\alpha$ of the total scale composed of these four items (Feedback) was 0.81. Excluding one item ("I know to whom and how I can send feedback about the system if I wish to do so") improved the $\alpha$ coefficient from 0.81 to 0.88 , and this item was therefore excluded from the final subscale.

The fifth factor comprised the strong loadings for five items reflecting external cooperation (loading - 0.72, 0.410.68 , explained the variance of $6 \%$, the strongest loading for item "Obtaining patient information from another organization often takes too much time") (negative loading). The $\alpha$ coefficient for the subscale (external cooperation) was 0.70 .

Three items reflecting internal cooperation were loaded on the sixth factor (loadings $0.44-0.71$ explained a variance of $5 \%$, the strongest loading for item "How well do the information systems support collaboration and information exchange between the physician and the nurses"). The $\alpha$ coefficient for the subscale (internal cooperation) was 0.63 .

Finally, two items were loaded on the seventh factor: Diagnostic imaging results are easily available on a regional level (factor loading 0.79) and Laboratory results are easily available and are logically presented on a regional level (loading 0.76 ). The last factor explained $4 \%$ of the variance between the items and the $\alpha$ coefficient for the subscale (Test results) was 0.66 .

In addition, the questionnaire included a statement on the additional features of the EPR systems: "Documentation of patient information needed for statistical purposes (=billing, national registries, reporting, etc.) takes too much time," "The patient's current medication list is presented in a clear format," "The information in the nursing record is easily readable." These were assessed on a 6 -point scale $(1=$ completely agree, $2=$ agree somewhat, $3=$ no opinion, $4=$ disagree somewhat, $5=$ disagree completely, $6=$ the system does not include the feature). For the analysis, the response scales were classified as $1=$ agree somewhat or completely, $0=$ disagree somewhat or completely/no opinion/the feature not included in the system.

\section{Statistical Analysis}

The relationships between the dependent and independent variables were analyzed as univariate associations by Pearson's correlation coefficients and by hierarchical multivariable regression analyses. Multivariate regression analyses were chosen because the dependent variables were continuous composite variables. In the regression analyses, the independent variables were entered in the equation in four steps: (1) background factors, (2) the principal brand of the EPR system, (3) experience in the use of electronic systems, and (4) usability factors and additional features of the system.

\section{Results}

\section{Results of the Univariate Analysis}

In the univariate analysis, specialized physicians reported somewhat less time pressure compared with those nonspecialized or in specialist training $(F=4.3, p<0.05)$, while those in training reported less job control compared with those specialized or nonspecialized ( $F=62.38, p<0.001$ ). Time pressure was more common in health centers compared with public hospitals and private practices $(F=222.22$, $p<0.001$ ), while highest job control was reported by those working in private practices and the lowest job control by those working in public hospitals $(F=116.02, p<0.001)$.

Those using several patient record systems on a daily basis reported more time pressure and less job control. Longer experience in the use of EPRs was related to higher job control. Those who had participated actively in the development of patient record systems reported somewhat more time pressure and more job control ( $>$ Table 1 ).

- Table 2 shows the Pearson correlations between usability factors, time pressure, and job control. Strong time pressure and job control were both particularly associated with lower user friendliness and higher technical problems.

Those who agreed with the statement that documentation of patient information for statistical purposes was time consuming reported more time pressure (mean $=3.69$, standard deviation $[S D]=1.03$ vs. mean $=3.20, S D=1.09$ among those not agreeing, $F=173.12, p<0.001$ ) and lower job control (mean $=3.94, \mathrm{SD}=0.85$ vs. mean $=4.09$, SD $=0.86$ among those not agreeing, $F=24.79, p<0.0 .001$ ). Those agreeing with the statement that nursing records were easily readable reported lower time pressure (mean $=3.29$, $\mathrm{SD}=1.10$ vs. mean $=3.58, \mathrm{SD}=1.06$ among those who did not agree, $F=52.75, p<0.001$ ) and higher job control (mean $=4.20, \mathrm{SD}=0.77$ vs. mean $=3.91, \mathrm{SD}=0.88 \mathrm{among}$ those who did not agree, $F=52.75, p<0.001)$.

\section{Results of the Multivariate Analysis}

-Table 3 presents the results of the hierarchic multivariate regression analysis with time pressure and job control as independent variables. 
Table 1 Time pressure and job control according to physician's experience in the use of EPR systems (univariate analysis)

\begin{tabular}{|l|l|l|l|l|l|l|l|l|}
\hline \multirow{2}{*}{} & \multicolumn{2}{l}{ Time pressure } & \multicolumn{3}{l|}{ Job control } \\
\hline & Mean & SD & F-Value & $p$-Value & Mean & SD & F-Value & $p$-Value \\
\hline Used the main system for & & & 1.5 & $<0.214$ & & & 19.15 & $<0.0001$ \\
\hline$>6$ y & 3.45 & 0.06 & & & 4.10 & 0.02 & & \\
\hline $3-6$ y & 3.41 & 0.05 & & & 3.99 & 0.03 & & \\
\hline $1-3$ y & 3.52 & 0.04 & & & 3.86 & 0.04 & & \\
\hline$<1$ y & 3.51 & 0.03 & & & 3.78 & 0.05 & & \\
\hline Number of clinical systems logged into daily & & & 24.3 & $<0.0001$ & & & 30.35 & $<0.0001$ \\
\hline Maximum 1 & 3.28 & 0.03 & & & 4.15 & 0.03 & & \\
\hline 2 & 3.52 & 0.03 & & & 4.04 & 0.03 & & \\
\hline 3 & 3.70 & 0.04 & & & 3.92 & 0.03 & & \\
\hline 4 or more & 3.58 & 0.04 & & & 3.77 & 0.03 & & \\
\hline Participated in the development of patient record system & 4.03 & $<0.018$ & & & 29.83 & $<0.0001$ \\
\hline Actively & 3.63 & 0.07 & & & 4.30 & 0.05 & & \\
\hline Somewhat & 3.51 & 0.03 & & & 4.07 & 0.02 & & \\
\hline Not participated & 3.44 & 0.03 & & & 3.91 & 0.02 & & \\
\hline
\end{tabular}

Abbreviations: EPR, electronic patient record; SD, standard deviation.

Factors Associating with Time Pressure in the Final Multivariate Analysis

Background factors explained $13 \%$ of the variance in time pressure. Entering the main patient record system into the model in step 2 did not explain the additional share of variance, while entering the level of self-regarded experience of using EPR systems in the third step and usability factors in the fourth step increased the explanation for the share of variance by 1 and 3 percentage points, respectively. In the final, fully adjusted model, women reported more time pressure than men; those working in public hospitals or private practices or private hospitals reported less time pressure compared with those working in health centers. Those using several clinical systems daily and those who participated actively in the development of the systems often reported more time pressure compared with their counterparts. Of the usability factors, more frequent technical problems lead to higher time pressure. Those who felt that compiling patient statistics in the electronic system was time consuming reported more time pressure. Even if the EPR brand did not increase the share of variance in step 2, when brand $\mathrm{D}$ was chosen as a reference system with background factors constant, the EPR system brands A, B, and C were associated with less of a feeling of the need to hurry.

\section{Factors Associating with Job Control in the Final Multivariate Analysis}

Background factors explained $11 \%$ of the variance in job control. Entering the main patient record system into the model in step 2 explained an additional $1 \%$ of the variance in job control, an additional 2\% experience of the use of electronic systems in the third step, and an additional 3\%

Table 2 Pairwise Pearson's correlation coefficients between time pressure, job control, and EPR system usability factors

\begin{tabular}{|l|l|l|l|l|l|l|l|l|}
\hline & $\begin{array}{l}\text { Time } \\
\text { pressure }\end{array}$ & $\begin{array}{l}\text { Job } \\
\text { control }\end{array}$ & $\begin{array}{l}\text { User } \\
\text { friendly }\end{array}$ & $\begin{array}{l}\text { Perceived } \\
\text { benefits }\end{array}$ & $\begin{array}{l}\text { Technical } \\
\text { problems }\end{array}$ & Feedback & $\begin{array}{l}\text { External } \\
\text { cooperation }\end{array}$ & $\begin{array}{l}\text { Internal } \\
\text { cooperation }\end{array}$ \\
\hline Time pressure & 1.00 & & & & & & & \\
\hline Job control & -0.23 & 1.00 & & & & & & \\
\hline User friendly & -0.19 & 0.20 & 1.00 & & & & & \\
\hline Perceived benefits & -0.11 & 0.12 & 0.54 & 1.00 & & & & \\
\hline Technical problems & 0.23 & -0.22 & -0.67 & -0.43 & 1.00 & & & \\
\hline Feedback & 0.10 & -0.10 & -0.49 & -0.43 & 0.42 & 1.00 & & \\
\hline External cooperation & -0.06 & 0.12 & 0.49 & 0.43 & -0.39 & -0.35 & 1.00 & \\
\hline Internal cooperation & -0.06 & 0.14 & 0.49 & 0.47 & -0.37 & -0.32 & 0.41 & \\
\hline Test results & $0^{\mathrm{ns}}$ & $0.03^{\mathrm{ns}}$ & 0.27 & 0.25 & -0.15 & -0.17 & 0.39 & 1.00 \\
\hline
\end{tabular}

Abbreviations: EPR, electronic patient record; ns, nonsignificant.

Note: All correlation coefficients significant $(p<-0.001)$ except those with "ns." 
Table 3 Factors associated with time pressure and job control (hierarchical regression analysis)

\begin{tabular}{|c|c|c|c|c|c|c|c|}
\hline \multicolumn{2}{|c|}{ Explanatory variables, their distribution $(\%)^{\mathrm{a}} /$ means and $(\mathrm{SD})^{\mathrm{b}}$} & \multicolumn{6}{|c|}{$\begin{array}{l}\text { Summary of the results of hierarchical regression } \\
\text { analyses }\end{array}$} \\
\hline & \multirow[b]{2}{*}{$\%$} & \multicolumn{3}{|c|}{ Time pressure } & \multicolumn{3}{|c|}{ Job control } \\
\hline & & $\beta$ & & $\Delta R^{2}$ & $\beta$ & & $\Delta R^{2}$ \\
\hline Age & $48.5(10.9)$ & -0.031 & & & -0.024 & & \\
\hline \multicolumn{8}{|l|}{ Gender } \\
\hline Men & 38 & ref & & & ref & & \\
\hline Women & 62 & 0.095 & $g$ & & -0.088 & $\mathrm{~g}$ & \\
\hline \multicolumn{8}{|l|}{ Specialization } \\
\hline Nonspecialized & 11 & ref & & & ref & & \\
\hline Specialization on going & 22 & -0.052 & & & -0.045 & & \\
\hline Specialized & 67 & -0.033 & & & 0.108 & $g$ & \\
\hline \multicolumn{8}{|l|}{ Health care sector } \\
\hline Public & 77 & ref & & & ref & & \\
\hline Private & & -0.081 & & & 0.044 & & \\
\hline \multicolumn{8}{|l|}{ Employer } \\
\hline Public health center & 28 & ref & & & ref & & \\
\hline Public hospital & 54 & -0.137 & $g$ & & -0.094 & $f$ & \\
\hline Private sector & 18 & -0.264 & $g$ & $0.13^{g}$ & 0.093 & & $0.11^{\mathrm{g}}$ \\
\hline \multicolumn{8}{|c|}{ Principal electronic patient information system } \\
\hline $\mathrm{D}$ & 4 & ref & & & ref & & \\
\hline A & 25 & -0.108 & $\mathrm{e}$ & & 0.086 & $\mathrm{e}$ & \\
\hline B & 14 & -0.092 & $\mathrm{e}$ & & 0.021 & & \\
\hline C & 24 & -0.121 & f & & 0.004 & & \\
\hline \multicolumn{8}{|l|}{ Used the main system for } \\
\hline$>6 y$ & 49 & ref & & & ref & & \\
\hline $3-6 y$ & 25 & 0.009 & & & -0.016 & & \\
\hline $1-3 y$ & 17 & -0.032 & & & -0.063 & $f$ & \\
\hline$<1 \mathrm{y}$ & 9 & -0.023 & & & -0.042 & e & \\
\hline \multicolumn{8}{|c|}{ Number of clinical systems in daily use } \\
\hline Maximum 1 & 33 & ref & & & ref & & \\
\hline 2 & 29 & 0.023 & & & 0.013 & & \\
\hline 3 & 19 & 0.068 & $\mathrm{~g}$ & & 0.010 & & \\
\hline 4 or more & 19 & 0.027 & & & -0.031 & & \\
\hline \multicolumn{8}{|c|}{ Participated in development of patient record system } \\
\hline No & 52 & ref & & & ref & & \\
\hline Somewhat & 41 & 0.022 & & & 0.077 & $\mathrm{~g}$ & \\
\hline Actively & 7 & 0.055 & f & $0.01^{\mathrm{g}}$ & 0.079 & $g$ & $0.02^{\mathrm{g}}$ \\
\hline \multicolumn{8}{|l|}{ Usability factors $^{c}$} \\
\hline User friendliness & $2.79(0.84)$ & 0.013 & & & 0.029 & & \\
\hline Perceived benefits & $2.74(0.80)$ & -0.030 & & & 0.020 & & \\
\hline Technical problems & $2.82(0.87)$ & 0.126 & $g$ & & -0.073 & $f$ & \\
\hline Feedback & $3.88(0.96)$ & -0.022 & & & 0.014 & & \\
\hline External cooperation & $2.13(0.73)$ & -0.019 & & & 0.013 & & \\
\hline Internal cooperation & $3.40(0.89)$ & 0.005 & & & 0.033 & & \\
\hline Test results & $3.16(1.12)$ & -0.029 & & & 0.017 & & \\
\hline
\end{tabular}




\begin{tabular}{|c|c|c|c|c|c|c|c|}
\hline \multicolumn{2}{|c|}{ Explanatory variables, their distribution $(\%)^{\mathrm{a}} /$ means and $(\mathrm{SD})^{\mathrm{b}}$} & \multicolumn{6}{|c|}{$\begin{array}{l}\text { Summary of the results of hierarchical regression } \\
\text { analyses }\end{array}$} \\
\hline & \multirow[b]{2}{*}{$\%$} & \multicolumn{3}{|c|}{ Time pressure } & \multicolumn{3}{|c|}{ Job control } \\
\hline & & $\beta$ & & $\Delta R^{2}$ & $\beta$ & & $\Delta R^{2}$ \\
\hline \multicolumn{8}{|l|}{ Additional features of the system ${ }^{d}$} \\
\hline Compiling patient statistics time consuming & 58 & 0.096 & $g$ & & -.012 & & \\
\hline Patient's medication list in a clear format & 32 & 0.006 & & & 0.034 & & \\
\hline Nursing record is in easily readable & 32 & -0.035 & & $0.03^{g}$ & 0.075 & $\mathrm{~g}$ & $0.03^{g}$ \\
\hline
\end{tabular}

Abbreviation: SD, standard deviation.

an categorized variables.

bIn continuous variables.

In continuous variables, scales 1-5.

${ }^{\mathrm{d}}$ Cathegorical variable: $1=$ agree completely or somewhat, $0=$ no opinion/disagree somewhat/disagree completely.

e $p<0.05$.

${ }^{\mathrm{f}} \mathrm{p}<0.01$.

${ }^{\mathrm{g}} \mathrm{p}<0.001$

usability factors in the fourth step. In the final, fully adjusted model, women reported lower job control than men; those working in public hospitals reported less job control compared with those working in health centers. Those using several clinical systems daily reported lower job control, while those who had participated actively in the development of the systems reported higher job control. More common technical problems were related to lower job control while the experience that nursing records were easy to read was related to higher job control. When brand D was chosen as a reference system with background factors constant, brand A of the EPR systems was associated with better job control.

\section{Discussion}

Perceived time pressure and lessened job control were strongly associated with technical problems and poor usability. Job control decreased and time pressure increased with having to use several clinical systems on a daily basis. More time pressure was experienced if the documentation of patient information needed for billing, national registries, etc., was experienced to take too much time. The experience of easy readability of electronic nursing records was associated with better job control. Physician participation in EPR development increased the feeling of job control, though it also exerted more time pressure.

\section{Technical Properties}

As expected, technical problems were associated with time pressure; they appeared to pose an important threat to workrelated well-being. We have reported earlier ${ }^{10,13}$ that the physicians' experiences with the technical properties of EPR systems have not improved in 4 years; in some EPR brands, the situation has even deteriorated. The fact that the stability of IT systems affects the work-related well-being of health care personnel should be acknowledged not only by EPR systems vendors but also by the organizations that provide hardware and network connections. The stability of an EPR system is heavily dependent on IT infrastructure: hardware and network communications are usually provided by the organizations and are just as credible factors as the instability of the EPR.

Using several clinical systems on a daily basis led to the experience of time pressure and lessened job control. In addition to EPR, a physician may have to access different appliances and softwares, for radiology, laboratory results, HIE, and so on. In Finland, private sector tends to have fewer clinical systems in use than the public sector and also fewer logins. They also grade their EPR systems better and have less load factors than their peers in the public primary care. ${ }^{7,14}$ Multiple logins is one of the factors in EPR usage affecting work well-being that could be improved with system integrations and context management (i.e., the system recognizes patient and health care professional when changing between systems).

We chose to analyze time pressure and job control of different EPR brands in reference to EPR brand D, because in our previous studies ${ }^{10,13}$ it has been rated by physicians as one of the most usable EPR systems and has been graded better than average. The results show that systems A, B, and C were less associated with the feeling of hurry and system $A$ was more associated with experience of better job control. In previous studies, A, B, and C brands have not been graded as very usable systems, although all three systems are the most widely used systems in Finland; they have also been in use since the 1990s. The EPR system brand D is a relatively new system and has fewer users. The length of experience was controlled in the regression analysis, but there may be additional factors that were not covered by the study, which would explain the result, and thus further study is required.

\section{Documentation of Patient Information for Statistical Reporting and Nursing Record}

Documentation of patient information for statistical purposes (e.g., billing, national registries, or other administrative authorities) was experienced as time consuming and it appeared to 
exert time pressure on physicians. One-third of private physicians and 50 to $80 \%$ of their public sector colleagues find this documentation work too time consuming. ${ }^{10,14}$ Statistical or administrative purposes can be experienced as unnecessary work that is irrelevant for patient care, if it is done to compile national statistics (e.g., as it is in Finland for the Register of Primary Health Care Visits to analyze visits on a national level). In an American study, the use of "physician partners" who could perform the administrative components of visits resulted in a decrease in time pressure, shortened visits, and also higher patient satisfaction..$^{38}$ The financial implications and training of physician partners were issues left open in the study.

Finnish physicians have criticized the readability of the nursing record applications of EPR systems. ${ }^{10-13}$ According to our results, easy access and understandable nursing record provide physicians with more job control. A good and usable nursing record can give the physician a good oversight on the status of the patient during rounds or visits and lead to a better base for the physician's decision making and hence to better job control.

\section{Physician Participation in EPR Development}

Physicians participating in IT development tended to experience more feelings of time pressure, but these same physicians felt they have better job control. User participation in development takes time away from clinical work, but could lead to better job control. However, the physicians experiencing better job control may be the ones who wish to participate in IT development. IT organizations and physicians' opinions about user involvement in development work differ: the physicians feel that there should be more involvement, but IT organization representatives perceive that there is enough participation. ${ }^{39,40}$ These studies suggest that better results could be gained by developing users' work practices at the same time as software development, that IT developers should visit the working places of the users, and that physicians involved in IT development should not be overlooked. Our results suggest that health care organizations should provide a timeframe for their users to participate in development work to relieve the time pressure experienced by the physicians.

\section{The Impact of Background Factors on Work-Related Well-being}

The physicians' background characteristics appeared to affect work well-being more substantially than the properties of the EPR systems. Time pressure and job control varied depending on gender, working sector, and the specialty of the physician. Those who are specializing tended to have less job control, which correlates with previous studies ${ }^{41,42}$ and can be explained by the training phase as they are learning only their specialty. Specialized physicians may also have less feelings of being rushed, due to having more expertise. In the multivariate analysis, the EPR systems used in the private health care sector associated less with the feeling of time pressure than the ones used in the public sector. According to a study conducted in Finland, physicians working in the private sector experienced better containment of work, job control, and work satisfaction in general. ${ }^{41}$ Moreover, they have given their EPRs more positive usability assessments. ${ }^{14,15}$ The requirements of EPR systems in national private health care are less complex than in the public sector, as the context of the work is mostly specialist consulting in definite issues and more complex and critically ill patients are treated in public sector.

Longer experience of the use of EPRs is associated with better job control. Familiarity with the system may reinforce the experience of job control. In our previous study, ${ }^{10}$ physicians found that they do not receive enough training in the use of the systems. Moreover, knowing the workflows and remembering the pitfalls of the systems help individuals to use the systems in a more controlled manner. Introduction and training of system use should always be well and carefully planned, also for system upgrades including changes in functionality.

\section{Limitations and Weaknesses}

The overall effect of work satisfaction on how physicians experience their EPRs is hard to distinguish from EPR's impact on work satisfaction. Physicians with good job control and time management may experience the use of EPRs easier and more usable than their peers, who are coping with experience of being hurried and having less job control. The methodology in the multivariate hierarchical regression analysis should remove most of these differences, but this cannot be ruled out as a confounder factor. Our study is a cross-sectional study, but considering the sample size, associations can be made.

Less than one quarter of Finnish physicians replied to the web-based questionnaire. However, we evaluate that our study sample was a representative sample of Finnish physicians by comparing our sample to Finnish Medical Association's register of physicians. The study questionnaire was piloted in 2010 and the reliability and validity of the questionnaire have been discussed in a study based on two study rounds in 2010 and $2014 .^{31,32}$ As the questionnaire was targeted to the whole physician population, we cannot take into account the daily workflows of some specialties (e.g., laboratory specialties, radiologists) when formulating the statements. The questionnaire was distributed only electronically, which may have excluded some potential respondents. However, we are not aware of any studies assessing whether those physicians who do not reply to electronic questionnaires would be more positive or negative with regard to the use of EPR systems.

As a secondary aim, we set to find differences between EPR software brands, but eventually there were no significant differences or further study was needed, and this hypothesis was not followed.

We did not use the full scale of Karasek's job content questionnaire; ${ }^{37}$ only seven questions were used of which two measured time pressure, and two accordingly job control. Due to the length of the original full questionnaire, which had altogether 34 questions, we carefully selected job content questions for those dimensions that the study was particularly interested in. This does not measure one's work well-being in depth, but gives a clear indication of time pressure and job control experienced. Because the number of our questions on the questionnaire was high, we grouped our usability questions into seven dimensions by explorative factor analysis 
instead of using the original questions. This does not measure usability factors in depth, but gives a clear indication of key HER-usability-related elements in physicians' daily work.

\section{Conclusion}

Our study is consistent with previous findings that EPRs affect physicians' work well-being. We were able to identify factors of EPR usage that influence the experience of time pressure and job control of physicians. These factors should be used in EPR development by vendors as well as legislators and health care organizations. As EPR systems have become one of the major factors in the work-related well-being of physician, the EPR software and hardware provided by the organization should be more stable, be better integrated, and have better usability to relieve time pressure and increase the job control of physicians. Improvements in login procedures, the ease of reading nursing records, and a reduction in the separate statistical documentation required could enhance better work well-being by relieving the mental strain experienced by physicians. Physician participation in EPR development is important and increases the feeling of job control; however, it also exerts more time pressure; thus, organizations should arrange time for developmental work.

In the future, the cross-sectional study is to be renewed in Finland. It would be interesting to find out if there are changes in the main EPR factors that affect work well-being. A similar study directed to other health care personnel such as nurses would also provide more feedback on which areas to concentrate on in the development work.

\section{Clinical Relevance Statement}

The problems related to usability and technical stability of healthcare IT systems pose a significant threat to the workrelated well-being of physicians. Fewer login procedures, easier readability of nursing records, and a decreased need for separate documentation for reporting purposes could enhance better work well-being. Physician participation in IT development would increase the feeling of job control, but at the cost of adding time pressure.

\section{Multiple Choice Question}

Physician participation in EPR development
A. Decreases the feeling of hurry.
B. Increases job control.
C. Helps understand technical problems.

Correct Answer: The correct answer is B. It increases job control, and also increases the feeling of hurry. Thus, health care organizations should allow time for development work for their workers.

\section{Protection of Human and Animal Subjects}

According to Finnish legislation, no ethical assessment or approval is mandatory for a study such as this. The Finnish law (Medical Research Act 1999/488, 2004/295, 2010/794) states medical research requiring the approval of an appropriate ethics committee as follows: research involving intervention in the integrity of a person, human embryo, or human fetus for the purpose of increasing knowledge or the nature of diseases in general. Our study is a behavioral study and compiled information on the social background and work history, placing on the market and physicians' experiences on EPR usability and work well-being. These cannot be regarded as providing sensitive, potentially harmful information about the participants.

According to the local and national ethical instructions for research (Finnish Advisory Board on Research Integrity: http://www.tenk.fi/en/request-for-ethical-review-in-human-sciences) instructions, this study did not require ethical approval. The autonomy of research subjects was respected, there was informed consent, no harm was possible for the subjects and confidentiality of the subjects, and research data were protected.

\section{Funding}

The study has been funded by the Finnish Work Environment Fund (project no. 116104), Strategic Research Council (SRC) at the Academy of Finland (project nos. 303604 and 303605), and the Finnish Ministry of Social Affairs and Health (project no. 514916001).

\section{Conflict of Interest}

None.

\section{References}

1 Laur A. Fear of e-Health records implementation? Med Leg J 2015; 83(01):34-39

2 Chen Y, Lorenzi N, Nyemba S, Schildcrout JS, Malin B. We work with them? Healthcare workers interpretation of organizational relations mined from electronic health records. Int J Med Inform 2014;83(07):495-506

3 Poissant L, Pereira J, Tamblyn R, Kawasumi Y. The impact of electronic health records on time efficiency of physicians and nurses: a systematic review. J Am Med Inform Assoc 2005;12(05):505-516

4 Vishwanath A, Singh SR, Winkelstein P. The impact of electronic medical record systems on outpatient workflows: a longitudinal evaluation of its workflow effects. Int J Med Inform 2010; 79(11):778-791

5 Friedberg MW, Chen PG, Van Busum KR, et al. Factors affecting physician professional satisfaction and their implications for patient care, health systems, and health policy. Rand Health $Q$ 2014;3(04):1

6 Heponiemi T, Vänskä J, Aalto A, Elovainio M. Changes in stress factors and psychosocial resources among Finnish physicians between 2006 and 2010. Suom Laakaril 2012;67(47):3491-3495

7 Vänskä J. Lääkärien työolot ja terveys 2015. 2016; Available at: https://www.laakariliitto.fi/site/assets/files/1266/1_k_rin_ty_olot_ja_terveys_2015_tuloksia.pdf. Accessed October 1, 2016

8 Kuusio H, Heponiemi T, Aalto AM, Sinervo T, Elovainio M. Differences in well-being between GPs, medical specialists, and private physicians: the role of psychosocial factors. Health Serv Res 2012; 47(1, Pt 1):68-85

9 Aalto AM, Elovainio M, Heponiemi T, Hietapakka L, Kuusio H, Lämsä R. Doctors and nurses of foreign origin in Finnish health care - challenges and possibilities. 2013;7 
10 Vainiomäki S, Hyppönen H, Kaipio J, Reponen J, Vänskä J, Lääveri T. Electronic Patient Record systems evaluated by brand in 2014. Suom Laakaril 2014;69(49):3361-3371

11 Vänskä J, Viitanen J, Hyppönen $\mathrm{H}$, et al. Doctors critical of electronic patient record systems. Suom Laakaril 2010; 65(50-52):4177-4183

12 Winblad I, Hyppönen H, Vänskä J, et al. Electronic patient record systems evaluated by make of product: further development required in all cases. Suom Laakaril 2010;65(50-52):4185-4194

13 Vänskä J, Vainiomäki S, Kaipio J, Hyppönen H, Reponen J, Lääveri T. Electronic Patient Record systems as physicians' tools in 2014: no significant changes in user experience reported by physicians. Suom Laakaril 2014;69(49):3351-3358

14 Lääveri T, Vainiomäki S, Kaipio J, et al. Assessment of private sector electronic Patient record systems in 2014. Suom Laakaril 2015;70(23):1660-1667

15 Lääveri T, Winblad I, Hyppönen H, Reponen J, Viitanen J, Antila KJ. EPR systems in private sector assessed, receiving criticism but also praise. Suom Laakaril 2011;66(19):1565-1571

16 Mamykina L, Vawdrey DK, Stetson PD, Zheng K, Hripcsak G. Clinical documentation: composition or synthesis? J Am Med Inform Assoc 2012;19(06):1025-1031

17 Victores AJ, Coggins K, Takashima M. Electronic health records and resident workflow: a time-motion study of otolaryngology residents. Laryngoscope 2015;125(03):594-598

18 Street RL Jr, Liu L, Farber NJ, et al. Provider interaction with the electronic health record: the effects on patient-centered communication in medical encounters. Patient Educ Couns 2014; 96(03):315-319

19 Reponen J, Kangas M, Hämäläinen P, Keränen N. Use of information and communications technology in Finnish health care in 2014. Current situation and trends. Terveyden ja hyvinvoinnin laitos (THL). National Institute for Health and Welfare. 2015;12.

20 Valvira. Health technology. 2015; Available at: http://www.valvira.fi/web/en/healthcare/health-technology. Accessed November 29,2015

21 Nummi VM. Inadequacies are frequently reported. Suom Laakaril 2012:930

22 Elovainio M, Vahtera J, Kivimäki M. Occupational justice and work force health. Kansanterveys 2006;(10):10-11

23 Lindfors PM, Heponiemi T, Meretoja OA, Leino TJ, Elovainio MJ. Mitigating on-call symptoms through organizational justice and job control: a cross-sectional study among Finnish anesthesiologists. Acta Anaesthesiol Scand 2009;53(09):1138-1144

24 Heponiemi T, Sinervo T, Vänskä J, Halila H, Elovainio M. Physicians' and nurses' problems in connecting work and family life. Sosiaalilääketieteellinen Aikakauslehti 2009;46(01):14-22

25 Heponiemi T, Sinervo T, Räsänen K, Vänskä J, Halila H, Elovainio M. Health and well-being of Finnish physicians and registered nurses -project report. Raportteja/Sosiaali- ja terveysalan tutkimus- ja kehittämiskeskus 2008;(35)
26 Töyry S. Burnout and self-reported health among Finnish physicians. Kuopion yliopiston julkaisuja D Lääketiede 2005(365)

27 Elovainio M, Heponiemi T, Vänskä J, et al. How well are Finnish physicians in the 21st century? Suom Laakaril 2007; 62(20-21):2071-2076

28 Aalto AM, Heponiemi T, Keskimäki I, et al. Employment, psychosocial work environment and well-being among migrant and native physicians in Finnish health care. Eur J Public Health 2014;24(03):445-451

29 Munyisia EN, Yu P, Hailey D. Does the introduction of an electronic nursing documentation system in a nursing home reduce time on documentation for the nursing staff? Int J Med Inform 2011; 80(11):782-792

30 Carayon P, Wetterneck TB, Alyousef B, et al. Impact of electronic health record technology on the work and workflow of physicians in the intensive care unit. Int $\mathrm{J}$ Med Inform 2015; 84(08):578-594

31 Hyppönen $H$, Hämäläinen $P$, Reponen J. Questionnaires of the 2014 eHealth and eWelfare surveys. 2015; Available at: http:// urn.fi/URN:ISBN:978-952-302-563-9. Accessed March 20, 2016

32 Kaipio J. Usability in healthcare: Overcoming the mismatch between information systems and clinical work. Helsinki, Finland: Department of Computer Science and Engineering, Aalto University; 2011

33 Kaipio J, Lääveri T, Hyppönen $\mathrm{H}$, et al. Usability problems do not heal by themselves: National survey on physicians' experiences with EHRs in Finland. Int J Med Inform 2017;97:266-281

34 Parmanne P, Ruskoaho J, Vänskä J. Labour market survey 2014. 2014

35 Harris P. The nurse stress index. Work Stress 1989;(03):335-346

36 Kivimäki M, Lindström K. Job stress and well-being of care providers: development of a standardized survey instrument. Hoitotiede 1992;4(03):115-124

37 Karasek R, Brisson C, Kawakami N, Houtman I, Bongers P, Amick B. The Job Content Questionnaire (JCQ): an instrument for internationally comparative assessments of psychosocial job characteristics. J Occup Health Psychol 1998;3(04):322-355

38 Reuben DB, Knudsen J, Senelick W, Glazier E, Koretz BK. The effect of a physician partner program on physician efficiency and patient satisfaction. JAMA Intern Med 2014;174(07):1190-1193

39 Martikainen S, Viitanen J, Korpela M, Lääveri T. Physicians' experiences of participation in healthcare IT development in Finland: willing but not able. Int J Med Inform 2012;81(02):98-113

40 Martikainen S, Korpela M, Tiihonen T. User participation in healthcare IT development: a developers' viewpoint in Finland. Int J Med Inform 2014;83(03):189-200

41 Heponiemi T, SinervoT, Vänskä J, Halila H, Elovainio M. Job control and organisational justice in physicians' work. Suom Laakaril 2010;65(44):3609-3614

42 Sumanen M, Heikkilä T, Hyppölä H, et al. Physician 2013 study: Physicians are satisfied with their vocational choice. Suom Laakaril 2015;70(34):2084-2089 


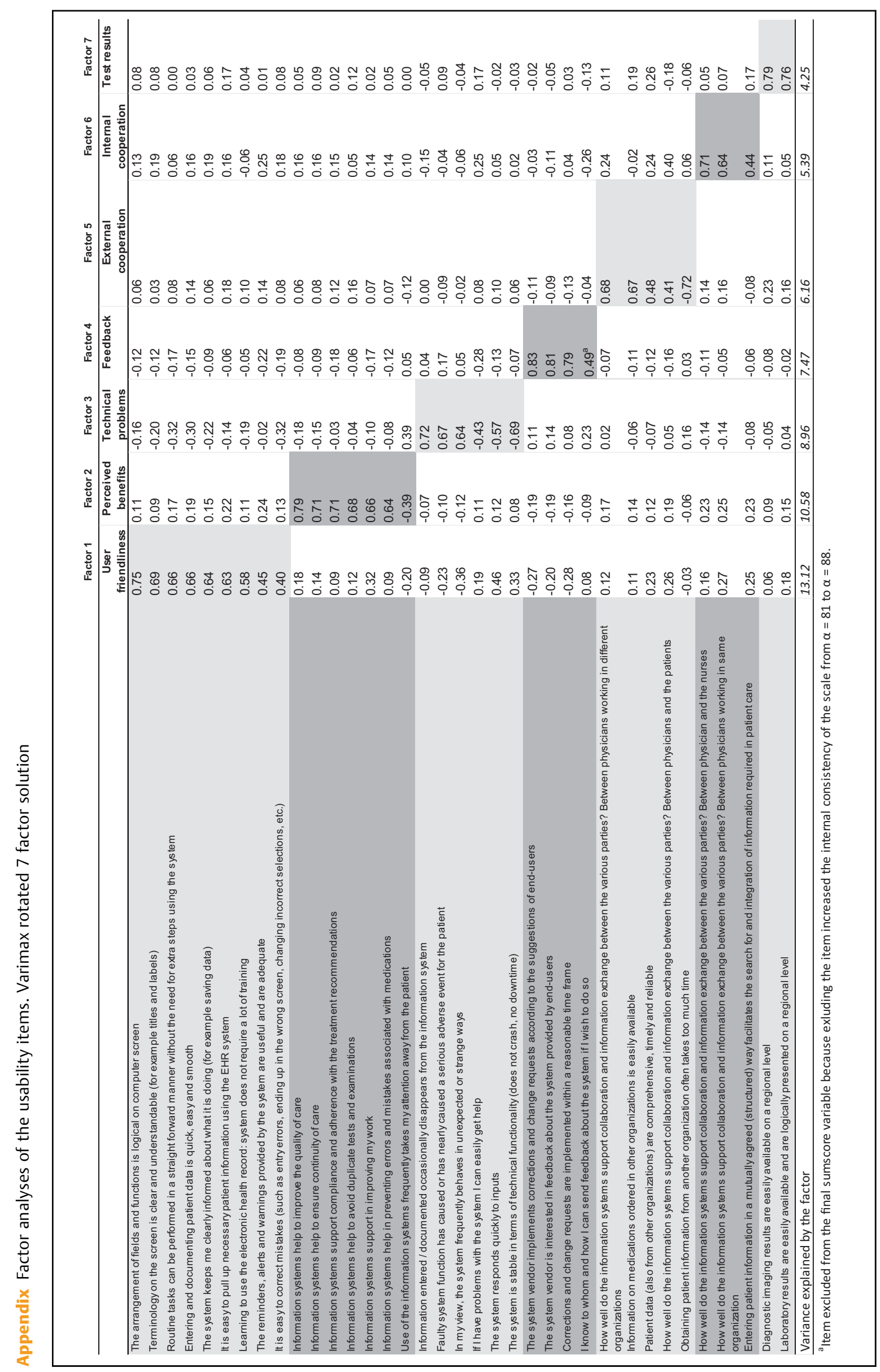

